\title{
Analysis of blasting seismic impact on underground mining workings under the conditions of the Magnezitovaya mine
}

\author{
Vyacheslav Kutuev $^{1 *}$, Pavel Menshikov ${ }^{1}$, Sergey Zharikov ${ }^{1}$ \\ ${ }^{1}$ Institute of Mining of the Ural branch of the Russian Academy of Sciences, 620075, 58, Mamina- \\ Sibiryak, Ekaterinburg, Russia
}

\begin{abstract}
Seismic impact of technological explosions on underground mining workings of the Magnezitovaya mine was assessed. Seismic stability of rocks of the Magnezitovaya mine was determined and safe distances from technological explosions have been calculated by the admissible seismic effect for rocks. URAN and Minimate Plus seismic recorders with three-component seismic receivers were used to establish the dynamic impact on the mine workings. Based on comparison of calculated values and experimental measurements, the recommendations are given for explosive mass limitation at a slowing-down stage at a level of minimum dangerous values for technological explosions in underground mine. It is established that the blasting operations carried out at the Magnezitovaya mine of PAO Magnezit Combine with fan longhole stopping were performed with the seismic impact safety of underground technological explosion and will not lead to the loss of rock mass stability near the underground workings. Relevance of these studies is to ensure industrial safety of underground mining operations.

Keywords: explosion seismic impact, blasting operations, seismic recorders, industrial safety, safe distances, maximum velocity of seismic fluctuations, permissible speed of fluctuations, seismic stability
\end{abstract}

\section{Introduction}

The seismic impact of technological explosions on underground workings is among the numerous factors predetermining mining safety, which is of practical significance under the conditions of the Magnezitovaya mine of PAO Magnezit Cimbine. The aim of the research is to study the conditions of seismic stability of the mine workings and to develop the methods of calculating the seismic safe distances from the explosion site. The scientific basis of the research is to measure the velocity of seismic fluctuations of rocks and to determine its permissible value.

\footnotetext{
* Corresponding author: slavik1988@mail.ru
} 


\section{Methods of Research}

To determine the permissible value of the velocity of seismic stress fluctuations, it is necessary to set the permissible value in the rock mass, which is in accordance with the seismic stability condition of the mine working [1]:

$$
\left[\sigma_{\mathrm{st}}\right]+\left[\sigma_{\mathrm{dyn}}\right] \leq \sigma_{\mathrm{per}},
$$

where $\left[\sigma_{\mathrm{st}}\right]$ - static stress in the rock mass surrounding the working, MPa; $\left[\sigma_{\mathrm{dyn}}\right]-$ dynamic stress in the rock mass (near the mine working), $\mathrm{MPa} ; \sigma_{\text {per }}$ - permissible stress value, MPa.

Values of tensile strength limits for the sample and the rock mass differ significantly (5 - 10 times and more). It is possible to estimate reliably the value of static limit of the rock mass strength only experimentally, which is impossible at initial design stages. In some cases it is possible to make an approximate calculation taking into account the average structural weakening coefficient and on the basis of the rock strength certificate. In rough approximation, the static tensile strength limit of rocks $\left(\sigma_{\text {per }}\right)$ can be taken as the permissible stress value $\left(\sigma_{t}\right)$ increased by $10-30 \%[2]$.

In [1] there is a formula to calculate the permissible velocity of the rock mass drift. The analysis of the formula, its transformation and comparison with actual measurement data showed that the values are slightly underestimated and are on the average up to $79 \%$ of the measured values. When the values are converted, rounding also results in an error reducing the value by 4 percent. In general, about $75 \%$ of the average actual value is obtained. Accordingly, the expression is used in the following form:

$$
v_{\mathrm{p}}=\frac{\sigma_{\text {per }}}{\gamma C} 2604.1, \mathrm{~m} / \mathrm{s},
$$

where $\sigma_{\text {per }}$ - permissible value of stresses, MPa; $\gamma$ - rock density, $\mathrm{t} / \mathrm{m}^{3} ; C$ - sound velocity in rock, $\mathrm{m} / \mathrm{s}$.

The velocity of seismic vibrations depending on the explosive weight in a stage and the distance from the explosion to the protected facility can be determined according to [3] by the following expression (the distance to the facility is less than $1500 \mathrm{~m}$ ):

$$
v=K(\sqrt[3]{Q} / R)^{m}, \mathrm{~cm} / \mathrm{s},
$$

where $Q$ is the mass of simultaneously detonated charges (explosive weight in the deceleration stage), $\mathrm{kg} ; R$ is the distance to the facility, $\mathrm{m} ; K$ is the factor depending on the explosion conditions. The value of $K$ varies depending on the rocks at the explosion site and the rocks surrounding the working mine. $K=200$ in the case of an explosion of hard rocks and hard rocks surrounding the working mine. In the case of an explosion of hard rocks and semi-hard rocks surrounding the working mine $K=400$. In explosion of semihard rocks and semi-hard rocks surrounding the working mine $K=600 ; m$ - a seismic wave attenuation index. For distances up to $1500 \mathrm{~m}$, the seismic wave attenuation index can be assumed as 1.5 .

Then the dependence (3) can be presented as follows:

$$
v=K \sqrt{\frac{Q}{R^{3}}}, \mathrm{~cm} / \mathrm{s} .
$$


The purpose of formula (4) is to determine the seismic vibrations velocity in the rock mass. A distinction of the calculation for underground conditions is that a type of support also matters in addition to the rock mass, it is expressed by a seismic stability coefficient $K_{\text {ss }}$ (Table 1).

Setting the acceptable seismic vibration rate for a protected rock section, makes it possible to determine the distances at which blasting will not lead to a loss of the rock mass stability near underground workings.

To determine the permissible distances from the blasting site to the protected rock area, by converting formula (4), $R$, where $v_{\mathrm{p}}$ is calculated by formula (2), can be expressed and the expression will be as follows:

$$
R=\sqrt[3]{\frac{Q K^{2}}{v_{\mathrm{p}}^{2}}}, \mathrm{~m}
$$

During the design process, the weight of explosives at the deceleration stage should be calculated taking into account the properties of the rock mass and the characteristics of the protected workings. Vibration velocity should be calculated using formulas (2) and (3), and coefficient $\boldsymbol{K}$ and seismic vibration attenuation index $\mathbf{m}$ are determined by instrumental measurements. In the absence of the latter, it is possible to use multivariant calculations and their comparison, and in some cases the average dependence obtained by generalization of the results of seismic wave parameters research in rock massifs with hardness $f$ by Protodyakonov's scale from 8 to 16 [2]:

$$
v=225(\sqrt[3]{Q} / R)^{1.6}, \mathrm{~cm} / \mathrm{s}
$$

The safety of the driven workings is ensured if the actual displacement velocity $v$ does not exceed the permissible value $v_{\mathbf{p}}$ with regard to the support type. The support itself significantly increases the seismic stability of the workings and can be represented by the coefficient $K_{\mathrm{ss}}$ (Table 1 ). In this case, the permissible velocity of vibration is determined according to [3] taking into account the purpose of the workings (see Table 1 and expression (7)):

$$
v_{\mathrm{p}}=v / K_{\mathrm{ss}}, \mathrm{cm} / \mathrm{s}
$$

Table 1. Seismic stability coefficient for different types of support

\begin{tabular}{|l|c|}
\hline \multicolumn{1}{|c|}{ Support type } & $K_{s s}$ \\
\hline Unsupported & 1.0 \\
\hline Sprayed concrete & $1.2-1.6$ \\
\hline Screw or bolting & $1.6-2.0$ \\
\hline Concrete & 2.2 \\
\hline Steel arch & $2.5-3.0$ \\
\hline
\end{tabular}

\section{Calculation of rock seismic stability during blasting}

The calculation was performed in accordance with the Technical Assignment for the Magnezitovaya mine rocks. The necessary input data for seismic stability calculation in the 
provided geological materials are not given in full. Therefore a part of the calculation data is taken from reference literature [4 - 10] (see Table 2).

Table 2. Initial data and calculated values of rock seismic stability.

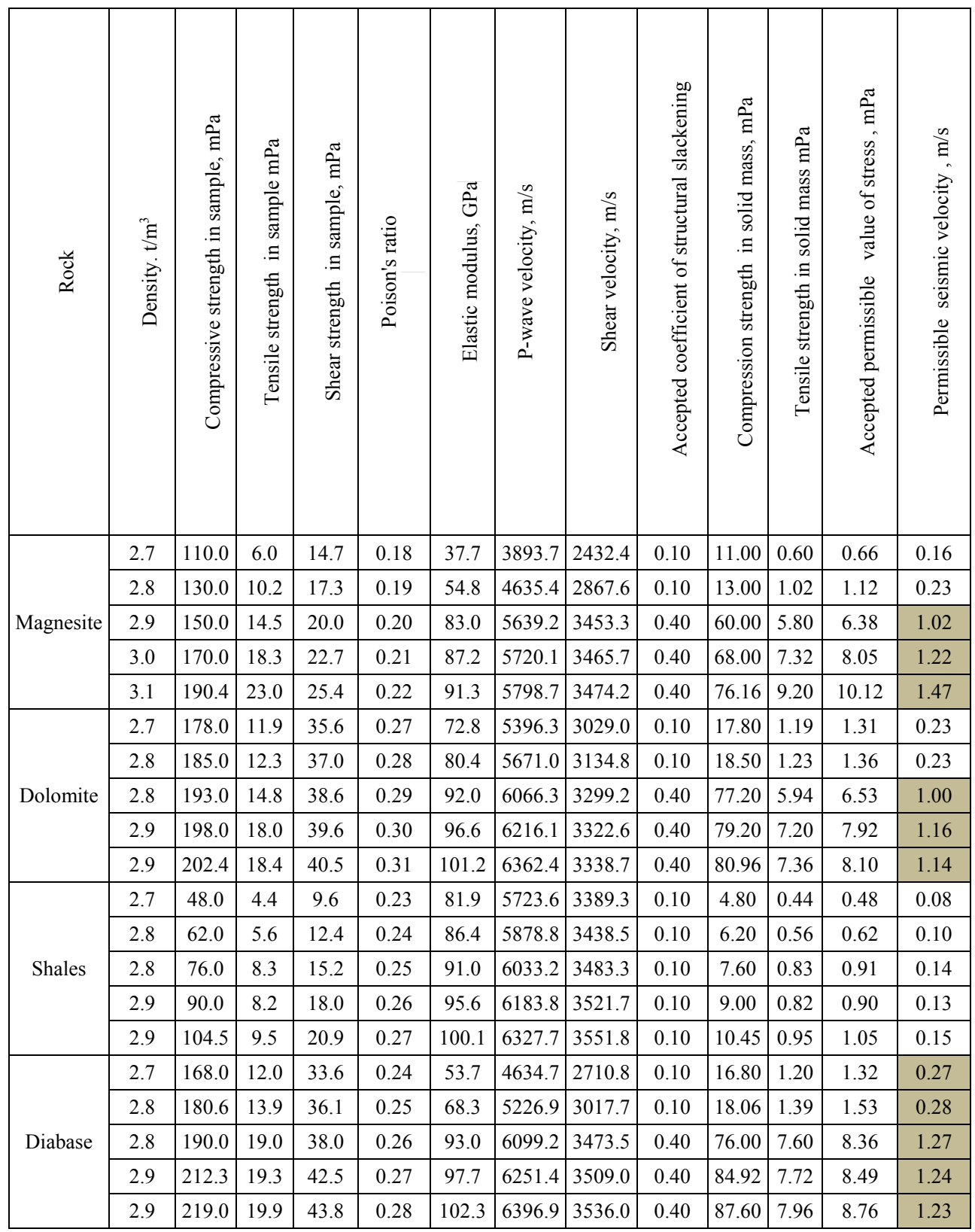

The permissible vibration velocity can be quite large. It should be taken into account that structural weakening and initial strength properties of rocks in the calculation, may differ from the properties of a particular section of the rock mass. In this connection, it is necessary to introduce a seismic limit, which for the important workings according to [3] is $0.24 \mathrm{~m} / \mathrm{s}$ and corresponds to the limit vibrations of 8 points of the earthquake [10]. 
In some cases (Table 2) there are observed the excesses of minimum allowed velocities (shown in grey). In subsequent calculations, these values are replaced by the limit value of $0.24 \mathrm{~m} / \mathrm{s}$.

\section{Results of instrumental measurements}

Measurements and recording of seismic vibration parameters were performed by a method of mechanical vibration multichannel recording using URAN digital seismic recorders with GS-20DX three seismic sensors (OOO Horizont, Russia, Ekaterinburg) and MiniMate Plus with Series III Standard Transducer seismic receiver (Instantel, Canada, Ontario) [11-14]. The parameters were registered by three components (axes): longitudinal - $\mathrm{x}$, transverse - $\mathrm{y}$ and vertical $-\mathrm{z}$.

The results of measurements of the seismic vibrations velocity and the schemes of seismic recorders location in underground mine workings relative to the explosion sites are given in Table 3 and in the figure 1, respectively.

Table 3. Results of instrumental measurements of seismic vibration velocities.

\begin{tabular}{|c|c|c|c|c|c|c|c|c|c|c|}
\hline \multirow{3}{*}{$\begin{array}{c}\text { Date of } \\
\text { explosion } \\
\text { (time of } \\
\text { explosion, } \\
\text { hour) }\end{array}$} & \multirow[t]{3}{*}{ Measurement site } & \multirow{3}{*}{$\begin{array}{l}\text { Recorder } \\
\text { (point } \\
\text { number) }\end{array}$} & \multirow{3}{*}{$\begin{array}{l}\text { Explosion } \\
\text { site }\end{array}$} & \multicolumn{5}{|c|}{ Velocity of seismic waves, $\mathrm{m} / \mathrm{s}$} & \multirow{3}{*}{ 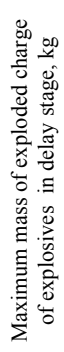 } & \multirow{3}{*}{ 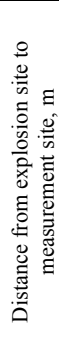 } \\
\hline & & & & \multicolumn{4}{|c|}{ Maximum } & \multirow[b]{2}{*}{ 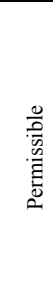 } & & \\
\hline & & & & 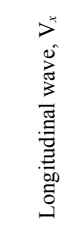 & 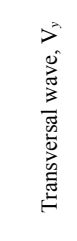 & 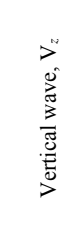 & 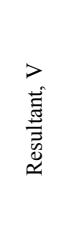 & & & \\
\hline \multirow[t]{4}{*}{$\begin{array}{l}03.02 .2020 . \\
(23: 00)\end{array}$} & $\begin{array}{c}\text { Chamber \#16, block \# 4, } \\
\text { lev. }+200 \mathrm{~m}\end{array}$ & $\begin{array}{l}\text { URAN } \\
\text { (p. 1) }\end{array}$ & \multirow{8}{*}{$\begin{array}{l}\text { Stope \# 1, } \\
\text { block \#5, } \\
\text { lev. }+220 \mathrm{~m}\end{array}$} & 0.0025 & 0.0057 & 0.0042 & 0.0075 & \multirow{8}{*}{0.24} & \multirow{8}{*}{84} & 62 \\
\hline & $\begin{array}{c}\text { Chamber \#5, block \# } 5 \\
\text { lev. }+200 \mathrm{~m} \\
\end{array}$ & $\begin{array}{l}\text { URAN } \\
\text { (p. 2) }\end{array}$ & & 0.0045 & 0.0033 & 0.0057 & 0.008 & & & 50 \\
\hline & $\begin{array}{c}\text { Junction of the block } 5 \\
\text { sublevel waste roadway and } \\
\text { orepass access } \\
\text { lev. }+220 \mathrm{~m}\end{array}$ & $\begin{array}{l}\text { URAN } \\
\text { (p. 3) }\end{array}$ & & 0.0377 & 0.0403 & 0.0428 & 0.0698 & & & 90 \\
\hline & $\begin{array}{c}\text { Chamber \#18, block \# 4, } \\
\text { lev. }+200 \mathrm{~m}\end{array}$ & $\begin{array}{l}\text { MiniMate } \\
\text { Plus } \\
\text { (p. 4) }\end{array}$ & & 0.0056 & 0.0039 & 0.0084 & 1.08 & & & 123 \\
\hline \multirow[t]{4}{*}{$\begin{array}{l}04.02 .2020 . \\
(23: 50)\end{array}$} & $\begin{array}{c}\text { Chamber \#16, block \# 4, } \\
\text { lev. }+200 \mathrm{~m}\end{array}$ & $\begin{array}{l}\text { URAN } \\
\text { (T. 1) }\end{array}$ & & 0.0057 & 0.0026 & 0.0058 & 0.0085 & & & 60 \\
\hline & $\begin{array}{c}\text { Chamber \#6, block \# 5, } \\
\text { lev. }+200 \mathrm{~m}\end{array}$ & $\begin{array}{l}\text { URAN } \\
\text { (p. 4) } \\
\text { (p. 2) }\end{array}$ & & 0.0072 & 0.0034 & 0.0089 & 0.0119 & & & 65 \\
\hline & $\begin{array}{c}\text { Junction of the block } 5 \\
\text { sublevel waste roadway and } \\
\text { orepass access } \\
\text { lev. }+220 \mathrm{~m}\end{array}$ & $\begin{array}{l}\text { URAN } \\
\text { (p. 3) }\end{array}$ & & 0.0228 & 0.021 & 0.0299 & 0.0431 & & & 85 \\
\hline & $\begin{array}{c}\text { Chamber \#18, block \# 4, } \\
\text { level. }+220 \mathrm{~m}\end{array}$ & $\begin{array}{l}\text { MiniMate } \\
\text { Plus } \\
\text { (p. } 4)\end{array}$ & & 0.013 & 0.0089 & 0.012 & 0.0198 & & & 92 \\
\hline
\end{tabular}




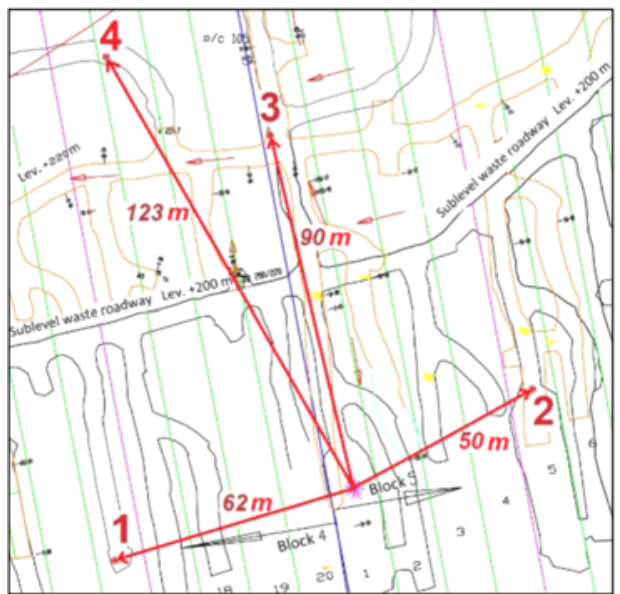

A

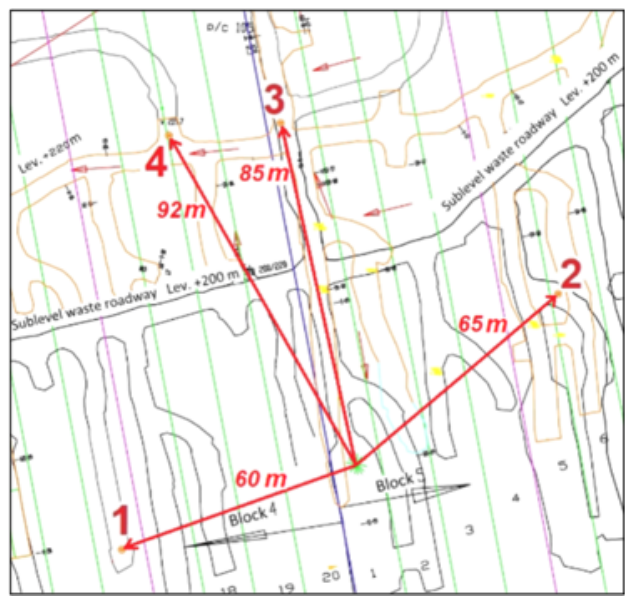

$\mathrm{B}$

Fig. 1. Layout of measurement points on February 03 (A) and February 04 (B), 2020, and blasting points (chamber \# 1, block \# 5, level $+220 \mathrm{~m}$ ).

\section{Conclusions}

The seismic stability of rocks of the Magnezitovaya mine was determined and safe distances from explosions were calculated by the permissible seismic effect. According to the calculations, for the explosive mass in the deceleration stage from $328 \mathrm{~kg}$ to $677 \mathrm{~kg}$, the safe distances for the rock mass without support, depending on the rock in which the explosion occurs, are as follows (vary according to the interval of the explosive mass in the stage):

- in subsurface soils - from 48 - $62 \mathrm{~m}$ (rocky) to 112 - $126 \mathrm{~m}$ (semi-rocky);

- in magnesite - from 37 - $49 \mathrm{~m}$ (rocky) to 87 - $98 \mathrm{~m}$ (semi-rocky);

- in dolomite - from 29 - $38 \mathrm{~m}$ (rocky) to 68 - $77 \mathrm{~m}$ (semi-rocky);

- in shales - from 59 - $77 \mathrm{~m}$ (rocky) to 138 - $156 \mathrm{~m}$ (semi-rocky);

- in diabase - from 30-39 m (rocky) to 70-80 m (semi-rocky).

Calculations by the expressions (5) and (6) have shown that more detailed consideration of the rock mass properties leads to increase of the calculated safe distance. It is logical because the properties of the semi-rocky massif are to be taken into account additionally. Considering the safety, from two variants of distances in a range it is always necessary to choose a greater variant, as in this case, probability of damage occurrence is less

The maximum resulting velocity of the ground seismic oscillations was $0.0698 \mathrm{~m} / \mathrm{s}$ near the junction of the sub-level waste roadway of the 5 th block and orepass access at the +220 $\mathrm{m}$ level during the technological explosion at Magnezitovaya mine on February 03, 2020. The measured maximum value of the seismic vibration velocity is 3.4 times less than the permissible velocity for important mine workings.

It is established that the blasting operations carried out at the Magnezitovaya mine of OOO Magnezit Combine at the fan longhole stoping have been performed with the safety of seismic underground technological explosion impact and will not lead to stability loss of the rock massif near the underground workings. 


\section{Acknowledgements}

The authors are grateful to their colleagues for the help in the research conducting, namely: A.S Flyagin. and S.S. Taranzhin (Junior Researchers of the Laboratory of Rock Destruction of Institute of Mining of the Ural branch, RAS).

The research has been carried out within the framework of State Proposal, theme \# 0405-2019-0005 (2019 - 2021), and with additional attraction of contract-based funding

\section{References}

1. V.A. Shchelkanov, P.S. Mironov, USSR: Drilling and blasting at open pits, 36, 91 (1972) (in Russian)

2. M.I. Kartuzov, N. V. Pazdnikov, Prediction of seismic safety of underground workings at explosions (IM MFM USSR, Sverdlovsk, 1982) (in Russian)

3. M.I. Kartuzov, N. V. Pazdnikov, Methods of ensuring seismic safe blasting technology (IM MFM USSR, Sverdlovsk, 1984) (in Russian)

4. Distribution and correlation of indices of physical rock properties (Nedra, Moscow, 1981) (in Russian)

5. Guidebook (inventory) of rock physical properties (Nedra, Moscow, 1975) (in Russian)

6. V.V. Rzhevsky, G.Ya. Novik, Fundamentals of rock physics (Nedra, Moscow, 1984) (in Russian)

7. V.V. Rzhevsky, Physico-technical parameters of rocks (Nauka, Moscow, 1975) (in Russian)

8. Minerals. Handbook in 4 Volumes (AS USSR, Moscow, 1960-1992). (in Russian)

9. Physical properties of rocks and minerals (petrophysics). Geophysisist handbook (Nedra, Moscow, 1984) (in Russian)

10. M.F. Drukovanyi Pit Blast Management Methods (Nedra, Moscow, 1973) (in Russian)

11. V.A. Kutuev. News of the Higher Institutions. Mining Journal 2, 25 (2020) (in Russian)

12. V.A. Kutuev, S.N. Zharikov, News of the Higher Institutions. Mining Journal 3, 50 (2020) (in Russian)

13. V.A. Kutuev, S.N. Zharikov, Mining Informational and Analytical Bulletin, 1(3), 380 (2020) (in Russian)

14. S.N. Zharikov, V.A. Kutuev, Problems of Subsoil Use. 2(21), 20 (2019) (in Russian) 